\title{
Strengthening emergency contraception in Nepal
}

Mahendra Pd. Shrestha

Sharif M.I. Hossain

Population Council

M.E. Khan

Population Council

Follow this and additional works at: https://knowledgecommons.popcouncil.org/departments_sbsr-rh

Part of the Demography, Population, and Ecology Commons, Family, Life Course, and Society Commons, and the International Public Health Commons How does access to this work benefit you? Let us know!

\section{Recommended Citation}

Shrestha, Mahendra Pd., Sharif M.I. Hossain, and M.E. Khan. 2008. "Strengthening emergency contraception in Nepal," FRONTIERS Final Report. Washington, DC: Population Council. 


\title{
Strengthening Emergency Contraception in Nepal
}

\author{
Mahendra P. Shrestha ${ }^{1}$ \\ Sharif M. I. Hossain ${ }^{2}$ \\ M.E. Khan ${ }^{2}$ \\ ${ }^{1}$ Nepal Fertility Care Centre \\ ${ }^{2}$ Population Council
}

September 2008

This study was funded by the generous support of the American people through the United States Agency for International Development (USAID) under the terms of Cooperative Agreement No HRN-A-00-98-00012-00 and In-house Project No. 5800.53104. The contents are the responsibility of the FRONTIERS Program and do not necessarily reflect the views of USAID or the United States Government.
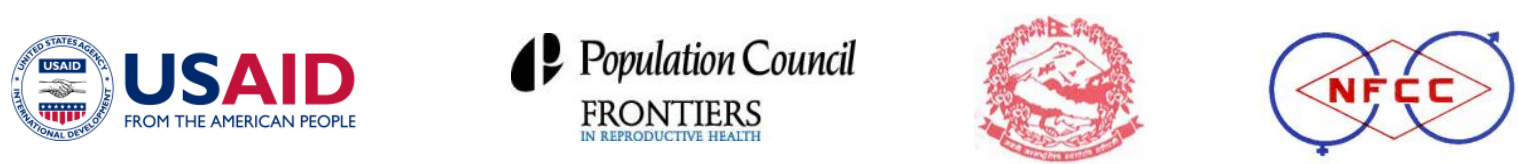
(C) 2008 The Population Council, Inc.

Suggested citation: Shrestha, Mahendra P., Sharif M.I. Hossain, and M.E. Khan. 2008.

"Strengthening emergency contraception in Nepal," FRONTIERS Final Report. Washington, DC: Population Council.

Any part of this publication may be reproduced without permission for limited distribution provided it is distributed without charge and the Population Council is acknowledged as the source. The Population Council would appreciate receiving a copy of any materials in which the text is used. 


\section{EXECUTIVE SUMMARY}

Emergency contraception pills (ECP) were incorporated into the National Medical Standards for Contraceptive Services and in the Clinical Protocols for Health Providers in Nepal in 2003. However, until recently, ECP was not included in actual service delivery and was not available through the government health facilities. A national workshop on emergency contraception was organized by the Family Health Division (FHD) within the Ministry of Health in 2004, and technical assistance was provided by the FRONTIERS Program of the Population Council. Among many conclusions from the workshop, one recommendation was that ECP should be introduced through the government family planning program to assist in reducing unwanted pregnancies. Based on the Population Council's past experiences with introducing and mainstreaming ECP services in Bangladesh and India, a phase-wise introduction of ECP in Nepal was recommended.

In the first phase, the ECP program was implemented in three districts of Kathmandu Valley (Kathmandu, Bhaktapur and Lalitpur) from August 2006 to December 2007 through a collaboration with the Department of Health Services (DoHS), Family Health Division (FHD), National Health Training Center (NHTC), and Nepal Fertility Care Center (NFCC). The overall objective of the program was to introduce ECP into the national family planning program and to identify any operational difficulties that the FHD may face to ensure smooth and efficient roll-out during country-wide scale-up.

Introduction of the ECP in Nepal followed the model developed and tested in Bangladesh. Information education and communication (IEC) materials, as well as training and evaluation tools, were translated from Bangladeshi to Nepali. As with the Bangladesh model, project activities were implemented in three phases: i) building capacity of the national program; ii) provision of services; and iii) evaluation of the intervention's impact. Intervention activities included the following:

- An orientation for government officials and stakeholders;

- Training of trainers (TOT) and of service providers;

- An orientation for Female Community Health Volunteers (FCHVs);

- Implementation of educational activities;

- Provision of ECP.

These interventions were evaluated through pre- and post-test comparative studies, observational studies, and in-depth interviews with clients.

A three-tier training model was adopted from the Bangladesh model to train 536 service providers and 1,938 FCHVs in Nepal. The service providers were trained by 12 master trainers during the TOT sessions. Service providers then trained FCHVs in educating potential clients in the community and in referring clients to facilities when necessary. Training evaluations, including pre- and post-training assessments, demonstrate that service providers' knowledge about ECP improved significantly after training. Additionally, monitoring checklists revealed that training was organized efficiently and completed satisfactorily in all sites. Retention of service provider knowledge about ECP was assessed four months after training, using questionnaires and interviews. Knowledge retention on certain issues was very high, and in some instances was greater than that assimilated after the initial training. 
Use of ECP was lower than expected during the nine-month intervention period. This may be due to continued limited accessibility to the method because FCHVs were not allowed to distribute ECP to community members and ECP was only available at health facilities managed by trained providers. Limiting availability of ECP to health facilities drastically restricted access, because Nepal's terrain is difficult to traverse and health facilities are located far from many of the women who may need ECP. It has been strongly recommended that allowing FCHVs to distribute ECP should be included in the scaling-up phase.

In-depth interviews with ECP users revealed that most women were already practicing some method of contraception; the most common reason for ECP use was misuse or malfunction of the regular contraceptive method. Examples included "condom burst" or "forgot to take injection before due date." A shift to increased use of long-acting contraceptive methods after using ECP disproves the assumption that ECP might be used as a regular contraceptive method and highlights the opportunity for ECP provision to be used to simultaneously promote other RH services and contraceptive methods.

Overall quality of ECP services was reported to be satisfactory among clients interviewed, with most providers including comprehensive counseling along with ECP provision. Most clients interviewed were able to recount accurate information about $\mathrm{ECP}$, including correct timing of doses and correct interval between doses. Interviews did reveal some topics that were not included in counseling as readily as others; for example, only 43 percent of clients reported receiving information about the effectiveness of ECP.

A few bottlenecks were identified, for example, informational brochures were not distributed to all ECP clients and many providers did not routinely provide ECP information to all family planning clients. To improve this situation, FHD hosted meetings with district authorities and encouraged all service providers to distribute ECP brochures and provide comprehensive ECP counseling as integral parts of family planning client visits.

The project findings suggest that Nepalese women continue to face an unmet need for ECP, and expansion of the program to additional regions within Nepal is necessary. ECP is currently only available in health facilities; for greater access, FCHVs should be allowed to distribute ECP; currently, they provide information and referrals. As they are the main contact persons for general and reproductive health needs within rural areas, allowing them to distribute ECP themselves would only improve access to ECP and ultimately decrease rates of unintended pregnancy.

Another finding that warrants attention is the consistently weak supervision and monitoring by the health system. Capacity-building is an urgent need, not only for the ECP program but also for all FHD services, and logistics of national and local systems must be improved for programs to be efficiently implemented. Both public and NGO systems are in need of longterm technical assistance to strengthen implementation of the ECP program as a number of barriers exist in the government's ECP scale-up plan, including for procurement and training.

Efforts to complementing funding from donors for ECP scale-up to national level have been partially successful. UNFPA-Nepal agreed to provide funding for the program scale-up in two districts in 2007 and more in 2008. UNFPA funding will support training efforts and purchasing of pills; NFCC will provide technical assistance in capacity-building efforts. 


\section{ABBREVIATIONS}

$\begin{array}{ll}\text { AHW } & \text { Auxiliary Health Worker } \\ \text { BCC } & \text { Behavior Change Communication } \\ \text { CPFSP } & \text { Clinical Protocols for Service Providers } \\ \text { DDA } & \text { Department of Drug Authority } \\ \text { DHO } & \text { District Health Officer } \\ \text { DOHS } & \text { Department of Health Services } \\ \text { DPHO } & \text { District Public Health Officer } \\ \text { ECP } & \text { Emergency Contraceptive Pill } \\ \text { FCHV } & \text { Female Community Health Volunteer } \\ \text { FHD } & \text { Family Health Division } \\ \text { FP } & \text { Family Planning } \\ \text { FPAN } & \text { Family Planning Association of Nepal } \\ \text { FRONTIERS } & \text { Frontiers in Reproductive Health Program } \\ \text { GO } & \text { Government Order } \\ \text { HC } & \text { Health Center } \\ \text { HP } & \text { Health Post } \\ \text { IEC } & \text { Information Education and Communication } \\ \text { MCHW } & \text { Maternal and Child Health Worker } \\ \text { MIS } & \text { Management Information System } \\ \text { MoHS } & \text { Ministry of Health Services } \\ \text { MR } & \text { Menstrual Regulation } \\ \text { NFCC } & \text { Nepal Fertility Care Centre } \\ \text { NGO } & \text { Non-Governmental Organization } \\ \text { NHEICC } & \text { National Health Education, Information and Communication Centre } \\ \text { NHTC } & \text { National Health Training Centre } \\ \text { NMS } & \text { National Medical Standard } \\ \text { OR } & \text { Operations Research } \\ \text { PHCC } & \text { Primary Health Care Center } \\ \text { PSI } & \text { Population Services International } \\ \text { SHP } & \text { Sub-Health Post } \\ \text { TA } & \text { Technical Assistance } \\ \text { TOT } & \text { Training of Trainers } \\ \text { UNFPA } & \text { United Nations Population Fund } \\ \text { USAID } & \text { United States Agency for International Development } \\ \text { VDC } & \text { Village Development Centre } \\ & \end{array}$




\section{ACKNOWLEDGMENTS}

The authors would like to thank all the service providers and all the DPHO who were actively involved in the ECP Program. Without their participation, the project would not have come into reality.

The authors would also like to thank NHTC for their participation in the program's training and its monitoring.

Special thanks to Dr. B. K. Suvedi for his interest and participation in all activities as well as his valuable suggestions for improvement of the program's delivery. Additionally, the project has immensely benefited from the technical assistance provided by the FRONTIERS program and the Population Council.

This project was possible due to the generous support from USAID, allowing us to carry out the first phase of the study. 


\section{TABLE OF CONTENTS}

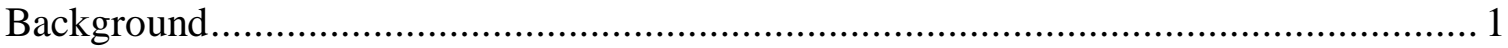

Statement of problem

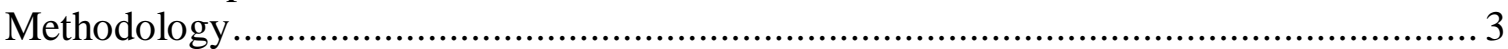

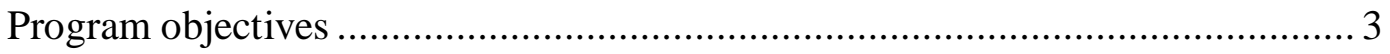

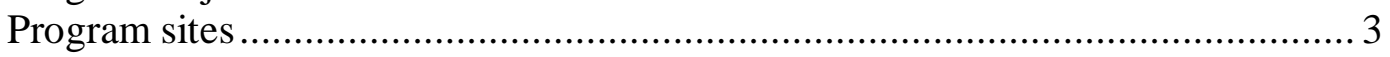

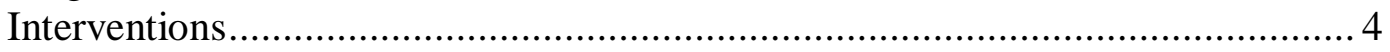

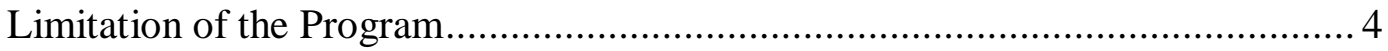

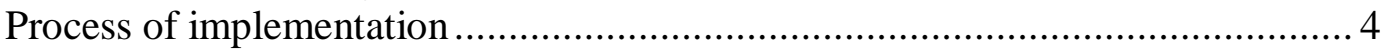

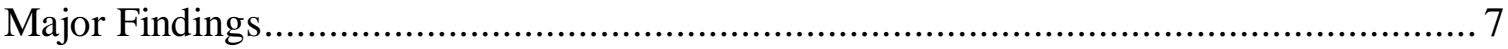

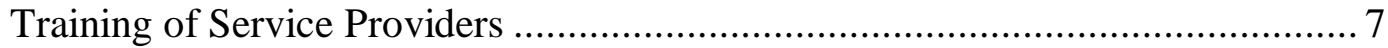

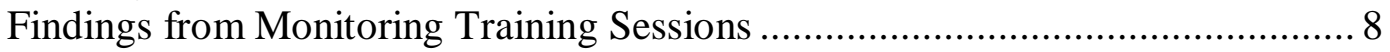

Retention of Service Providers' Knowledge ................................................. 9

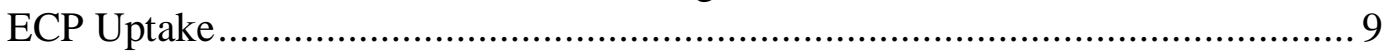

Sources of ECP information ...................................................................... 10

Socio-demographic Characteristics of ECP Users ....................................... 10

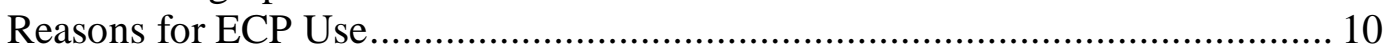

Findings from Client-Provider Interactions .............................................. 11

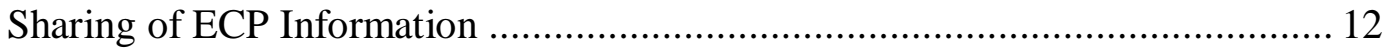

ECP User Knowledge about the Method ................................................ 12

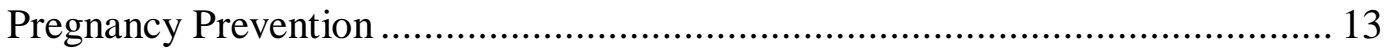

Use of Contraception Before and After the Use of ECP ............................. 13

Findings from Monitoring Service Provision ........................................... 13

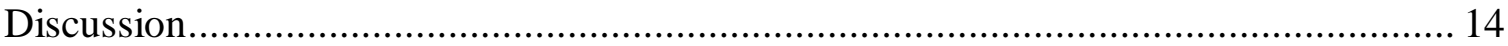

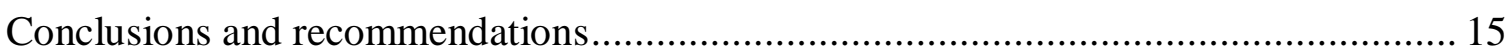

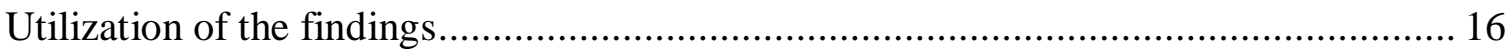

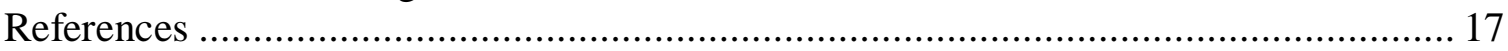




\section{LIST OF TABLES AND FIGURES}

Table 1: $\quad$ IEC materials distributed $\quad 5$

Table 2: $\quad$ Number of service providers trained, by district 7

Table 3: $\quad$ Percentage of correct answers assessing service provider's understanding of proper ECP use

Table 4: $\quad$ Use of ECP (October 2006 to November 2007) 10

Table 5: Findings from client provider interactions 12

Table 6: $\quad$ Use of contraception before and after the use of ECP 13

Figure 1: $\quad$ Implementation process 4

Figure 2: $\quad$ Percentage of correct answers assessing service providers' $\quad 8$

Figure 3: $\quad$ Percentage of correct answers assessing service providers' $\quad 8$ understanding of ECP functionality

Figure 4: $\quad$ Percentage of service providers correctly identifying ECP side effects 9

Figure 5: $\quad$ Percentage of correct answers in service provider's knowledge retention 9 test 


\section{BACKGROUND}

Emergency contraception (EC) was incorporated in the National Medical Standard (NMS) for Contraceptive Services and in Clinical Protocols for Health Providers in Nepal in 2003. The Emergency contraception pill (ECP) was included in the Comprehensive Family Planning Training Package (COFPTP) available to paramedics, and in 2004 was registered by the Department of Drug Authority (DDA) and introduced to the people. This national introduction was led by Population Services International (PSI) promoting the use of Postinor-2, through social marketing campaigns throughout the country. According to Nepal's Contraceptive Retail Sales company information, ECP sales have been substantially increasing since its introduction: 8,276 packets in September 2005, 17,824 in September 2006, and 11,275 in January 2007. However, ECP was only available privately until August 2006, at which time the ECP Nepal program was initiated and introduced into the national family planning program.

The National Workshop on Developing Sustainable Strategies for Introducing Emergency Contraception in Nepal was held in 2004, to assist ECP's introduction into the public system and gain united support for its implementation. The Family Health Division (FHD) and the Ministry of Health Services (MoHS) hosted the event; decision makers, program managers, researchers and donors attended. Associates from the FRONTIERS Program presented information on Bangladesh's and India's national ECP Programs and explained parallels and lessons learned between those neighboring country programs and Nepal's potential program. The Center for Research on Environment Health and Population Activities (CREHPA) presented their research on unprotected intercourse, unplanned pregnancies, abortions, and knowledge of providers on EC in Nepal, conveying an urgent need for ECP within Nepal's contraceptive method mix. With positive recommendations from the workshop attendees and guidance from the government's reproductive health objectives, the FHD and MoHS agreed to introduce ECP in Nepal, initially in three districts of Kathmandu Valley.

FHD is responsible for planning, supervising, and implementing family planning activities in Nepal. Family planning counseling and services are provided through all health service delivery points at different levels. The lowest level of service delivery is the Female Community Health Volunteers (FCHVs), who distribute certain contraceptive methods (such as condoms and oral contraceptive pills (ORS)) to women within the community, and also refer clients to health facilities for treatment and counseling. Their realm is not limited to reproductive health, and FCHVs provide services and referrals for general illnesses and conditions as well (DoHS 2002). Health facilities comprise the other service delivery levels in Nepal's system and include (in ascending order from lowest to highest level): 3,132 Subhealth Posts (SHPs); 705 Health Posts (HPs); 178 Primary Health Care Centers (PHCCs)/HCs; 61 District Public Health Offices (DPHO); 62 District Hospitals; 11 Zonal Hospitals; 5 Regional Health Directorates; and 5 Central Hospitals.

In July 2007, the Ministry of Health and Population, and the Government of Nepal published the National Medical Standard for Reproductive Health, Volume III: Maternal and Neonatal Care. This document identified a number of interventions to reduce maternal mortality and to potentially be used within the country's safe motherhood program. Two of these interventions are directly related to provision of ECP-access to family planning and management of the unwanted pregnancies - and contribute to promotion of women's health and reduction in maternal mortality. 


\section{STATEMENT OF PROBLEM}

According to the Nepal Demographic and Health Survey (NDHS) 2006, 56 percent of the currently married women in Nepal do not use any form of family planning, despite their universal knowledge of modern contraceptive methods. Moreover, 25 percent of Nepal's married women have an unmet need for family planning services (9\% for spacing and $16 \%$ for limiting births). Many of Nepal's births are unwanted-women desire an average of 2.5 births, yet give birth to an average of 4.1 births (NDHS 2006), and many result in abortion. Abortion is legal in Nepal, yet access is largely restricted to urban areas, and therefore unsafe abortions continue to occur. From March 2004 to December 2006, 106,288 women received abortions from public, private and NGO health facilities, yet many more undocumented abortions took place in Nepal, conducted by untrained providers in unhygienic conditions. Low social status of women, negative attitudes towards abortion, lack of knowledge, fear, shame, and limited access to health care services continue to drive women to seek abortions outside of the health system, putting themselves at risk for infections and possibly death.

During the last 10 years, the Ministry of Health $(\mathrm{MOH})$ has introduced several major safe motherhood interventions to fight abortions and improve women's health. A sharp decline in the nation's maternal mortality rate (MMR) has been documented as a result of these interventions - from 539 to 281 per 100,000 live births (NDHS 2006 and WHO 2004). Yet, many more deaths could be averted if the number of unwanted pregnancies were only decreased. Provision of ECP could play a significant role in preventing these pregnancies, along with the mix of other modern contraceptive methods and strong health systems and delivery.

Women in Nepal practice many ineffective harmful and non-harmful methods and procedures following unprotected intercourse to safeguard themselves from unwanted pregnancies (CREHPA 2004). These methods include oral intake of both edible and non-edible items like herbs, fruits, vegetables and harmful items like glass powder, and raw Vermillion powder. Women also perform physical activities such as getting up immediately after intercourse and walking, husband kicking wife from behind, pressing abdomen with stone grinder, squatting, massaging, urinating immediately after intercourse, etc. Furthermore, women also perform invasive procedures such as inserting finger and cleaning vagina with soap and water (CREHPA 2004). All these methods and procedures indicate desperation of women to avoid possible pregnancies that might result from unprotected intercourses. These findings are quite similar to the observation made in Bangladesh (Khan and Sharif 2001) and India (Mary and Khan 2005).

In Nepal, unprotected intercourse is common and women often do not have control over their body or their sexuality. One study in Nepal revealed that 10 to 20 percent of adolescents reported participating in pre-marital sex, yet only 9 percent of them reported using a method of contraception (CREHPA 2004). ECP could act as the necessary protection against pregnancy that these women and girls are in need of preventing unwanted pregnancy, dangerous abortions and other detrimental consequences of having a mistimed or unwanted child. ECP is also appropriate for use among women in compromised situations, such as those who have been raped, experienced misuse or failure of contraceptive methods, and those who have sex without an effective method of family planning (ICEC 2007 and WHO 1998). ECP plays a vital role in the protection in the method mix of contraceptive options and reproductive health. 
Currently in Nepal, ECP is available in urban areas through social marketing program spearheaded by PSI. Yet knowledge about this method and its proper use is still very limited among users as well as providers, and is continually unavailable in rural areas of the country. A study of doctors and paramedics in selected districts in Nepal revealed that very few FP service providers knew the proper usage of ECP as well as other pertinent details for its proper provision. Providers also lacked family planning counseling skills and had little or no access to educational aids to assist them in method provision and instruction (CREHPA 2003).

Considering all of these facts, the Ministry of Health and Population and the government of Nepal decided to introduce ECP in the National Family Planning Program. The program will be implemented in a phased manner-initially in the three districts of Kathmandu Valley (Kathmandu, Lalitpur, and Bhaktapur districts) and afterwards in additional districts throughout the country. This first implementation phase will serve to introduce ECP into public sector on a small scale, train necessary providers for ECP provision, identify operational strengths and weaknesses, and lastly, create a comprehensive implementation plan to guide the implementation of subsequent program phases. This report presents findings from this first phase.

\section{METHODOLOGY}

\section{Program Objectives}

The overall objective of this project was to provide technical assistance to the FHD, the MoHS, and the government of Nepal, in the introduction of emergency contraception into their National Family Planning Program. Specific objectives of this project included:

- To assist the FHD to introduce ECP in the Kathmandu Valley

- To translate and adopt the ECP manual, teaching aids, and IEC materials (developed by the Population Council) into the Nepali language

- To sensitize all concerned parties about ECP and its need among the population, as well as the importance of its incorporation into the National FP Program

- To develop a cadre of ECP trainers and to ensure quality of training for all potential ECP providers

- To introduce ECP provision and services in the National FP Program

- To develop a Management Information System (MIS) to assist in the monitoring of the national ECP services

- To document the lessons learned in this project and make recommendations for the scaling-up within following program phases

\section{Program Sites}

The first phase of the ECP Program was implemented in three districts of the Kathmandu Valley: Kathmandu, Lalitpur and Bhaktapur. All Sub-Health Posts (SHP), Health Posts (HP), Primary Health Care Centers (PHCC), and institutionalized family planning clinics under the DPHO participated in the initial phase of the program, however, specialized hospitals were not included. 


\section{Interventions}

The following activities took place during the ECP Program introduction:

- An ECP orientation for concerned government officials and representatives of stakeholders

- Training of trainers and training of service providers

- An ECP orientation for Female Community Health Volunteers (FCHVs)

- An IEC campaign focusing on ECP messages

- Provision of ECP product and counseling services.

To document and monitor these activities, methods including pre- and post-tests, service statistic collection, and service delivery observations were conducted.

\section{Limitations of the Program}

The study encountered several challenges during its planning and implementation. At the program's initiation, the MOH limited ECP provision to paramedics and doctors only; FCHVs were only authorized to educate women about ECP and provide referrals to health facilities where further services could be obtained. This restriction extensively reduced women's access to ECP services. A second barrier faced was the frequent transfer of trained service providers to areas outside of the program's intervention sites. Unfortunately, this challenge remained throughout the program's implementation and was never completely resolved. The health facilities' poor functioning further affected the efficient promotion of ECP. Service providers were many times not present in intervention centers where ECP services were to be distributed, and untrained staff members were the sole service providers.

\section{Process of Implementation}

The project was implemented in three phases: 1) capacity-building of the national program; 2) provision of services; and, 3) documentation of experiences. Figure 1 portrays this implementation process.

\section{Formation of Project Management} Committee (PMC): At the project's onset, a project management committee was formed to review the progress of the project, identify the bottlenecks, and develop an action plan according to the findings. Members of the PMC included Director FHD, district authorities, Population Council representatives, and the NFCC. The PMC met three times throughout the program's implementation.

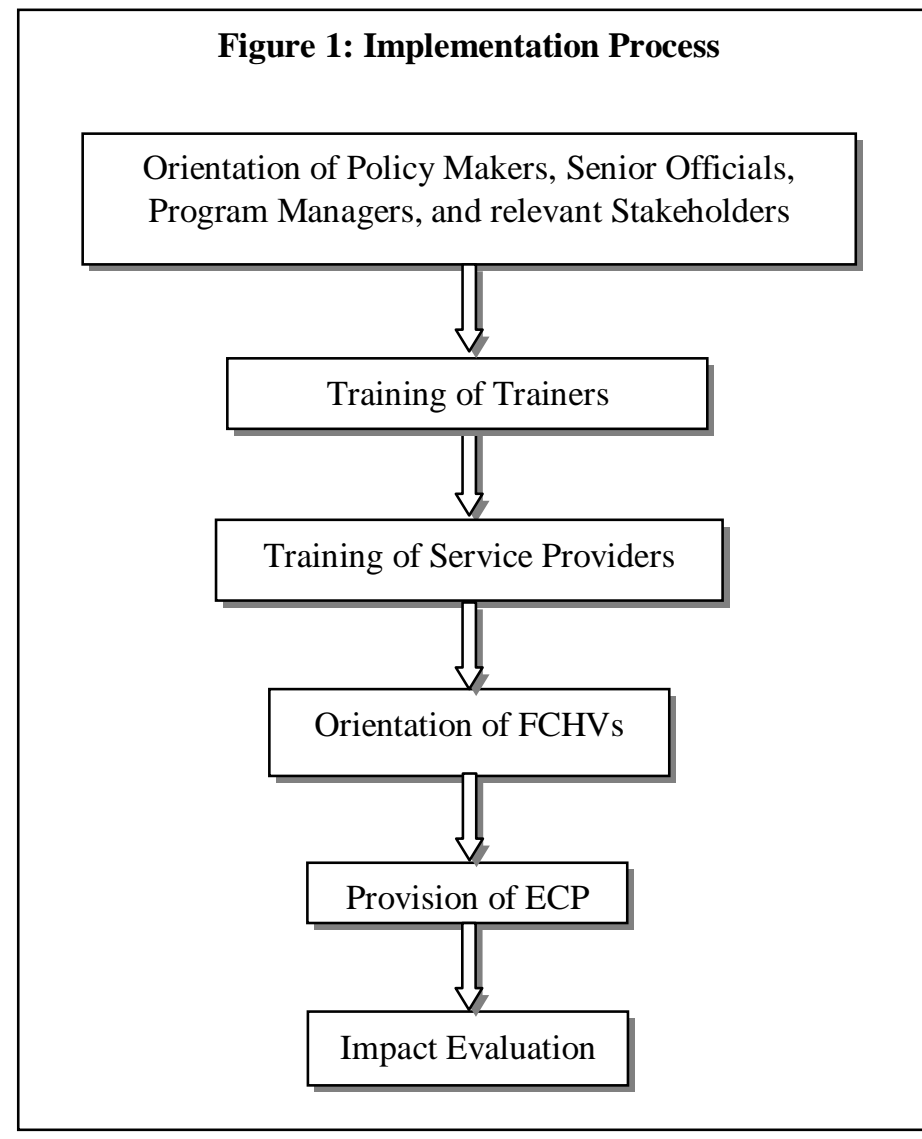


Orienting Relevant Government Officials and Stakeholders: Initially, a half-day orientation was organized for approximately 50 government officials $(\mathrm{MOH}$, DoHS, FHD, NHTC, DPHOs, and Municipalities) and research agencies to orient them on ECP and its role in the National Family Planning Program. This orientation addressed ECP in general, the program's objectives, and its strategic plan.

Development of Teaching and IEC Materials: The project used ECP teaching materials developed by Population Council, previously utilized in both Bangladesh's and India's respective ECP Programs. These IEC materials were reviewed, adapted, and produced in the Nepali language. The following materials were incorporated into the project's IEC materials:

- An ECP training manual

- Transparency sets for the trainers

- An ECP brochure for service providers

- A flipchart used during service provider training

- An ECP brochure for clients

- ECP information posters for clinics and trainings

Conducting Educational Activities: During the project, IEC materials for both providers and clients were printed and distributed within the three study districts (Table 1). DPHO used regular supply system of the district health office to distribute these materials to the different health facilities and providers. Service providers distributed ECP brochures in conjunction with ECP provision and counseling at intervention clinics. Women using temporary methods of contraception and eligible couples interested in receiving FP Table 1: IEC materials distributed counseling also received ECP counseling and

\begin{tabular}{|l|l|}
\hline Type of materials & $\begin{array}{l}\text { Number } \\
\text { distributed }\end{array}$ \\
\hline Provider's brochures & 4,000 \\
\hline Flip charts & 350 \\
\hline Posters & 2,500 \\
\hline Client brochures & 200,000 \\
\hline
\end{tabular}
IEC materials. Outside clinics, FCHVs, Mothers' Club members, and VDC members educated community members, providing brochures to women along with interpersonal communication and referrals.

Training of Trainers (TOT): A one-day training session was organized for trainers at NFCC in Kathmandu. NHTC conducted training in collaboration with members of the FHD and the NFCC. FRONTIERS provided backup and technical assistance during trainings. In addition to the 12 trainers from the DPHO districts, four officials from FHD and NHTC attended. Those trained all possessed a medical background and were selected based on their previous experience with health and family planning issues. After participating in the TOT, participants proceeded to train service providers within their respective districts.

The TOT included technical aspects of ECP (e.g. service delivery guidelines and ECP counseling), proper use of training materials, methods of monitoring quality, and efficiency of training sessions and methods of improvement, as well as ECP logistics management. Training manuals were distributed as a resource to be used during and after training.

Training of Service Providers: Trainings for service providers were organized at NFCC, District Public Health Office, Kathmandu and Korea Maitri Hospital, Bhaktapur. A team of four trainers in each district trained the service providers in a one-day session. A total of 545 service providers from 135 health facilities, and 41 health workers from three Municipal Corporations were trained. 
Service provider trainings included generalized elements (such as technical discussions, service delivery guidelines, and ECP counseling skills), and were also tailored to communityspecific needs. Transparencies and other job aides were utilized in each session. Pre- and post- tests were completed for monitoring and quality purposes.

Orientation of FCHVs: FCHVs are the major workforce of Nepal's Health and Family Planning Programs and provide the majority of the program's health education. They work at the community level and provide oral contraceptive pills, condoms, ORS, and other health commodities, as well as refer clients to health facilities for further services and counseling.

FCHVs were provided with a half-day orientation on ECP, led by Auxiliary Health Workers (AHWs) at the SHPs and HPs. This orientation included an overview of the role of ECP as a contraceptive method, as well as FCHVs' potential roles in ECP education, provision, and referral. A total of 1,938 FCHVs attended this orientation. No pre- and post-training tests were included in the FCHVs' orientation, as their education and literacy levels are low and any change in knowledge would have been difficult to assess.

Provision of ECP: Upon completion of training service providers, working in the clinic setting, received ECP to initiate distribution to clients. FCHVs were not eligible to distribute ECP packets, as they were deemed unable to maintain necessary records. FCHVs were limited to providing ECP education and referral services.

A total of 5,000 packets of ECP (Postinor 2) were distributed among service providers within the DPHOs of Kathmandu, Lalitpur, and Bhaktapur. The number of ECPs distributed to each DPHO was determined by the number of service delivery outlets within each district. ECP was available to the clients free of cost, and were distinguished from the private-market ECP provided by PSI with a label designating "Only For Free Distribution." Involving the DPHOs in ECP distribution ensured ECP's incorporation into Nepal's normal contraceptive delivery system and integrated ECP documentation into the service providers' records and reports.

Monitoring Quality of Providers Training: The quality of the service provider training was regularly monitored by district officials. Monitors used a checklist format to assess the quality of training sessions, and a survey to assess provider's retention of ECP knowledge at four months post-training.

Documentation of the Impact of Interventions: Program experiences and impact were evaluated and documented during the 15 months of the project activities. Client-provider interactions were observed, service statistics were analyzed using the MIS, and in-depth interviews with ECP clients were conducted.

Service providers completed forms (HMIS 11) where information about ECP use, reasons for use and, characteristics of ECP users was detailed. This information was collected in all districts and reported to the DPHO, followed by the central MIS of the FHD. In-depth interviews were conducted with 61 ECP users from the three intervention districts. Five nursing students were hired as interviewers; they were trained and oriented on ECP and counseling, program guidelines and methodology for proper in-depth interviews. Each student conducted 12 interviews with ECP users and gathered information about the clients' perceptions of ECP and their experiences at the clinics where ECP was supplied. 
Observations of some client-provider interactions took place to assess the quality of ECP services provided from a third-party perspective. Particular attention was taken on specific aspects of ECP provision and the quality of service delivery. Among other things, the presence of non-judgmental attitudes, the extent and detail of education and information provided about ECP, and the skill and effectiveness of the provider's counseling efforts were assessed during observations.

\section{MAJOR FINDINGS}

\section{Training of Service Providers}

A total of 2,483 service providers and 1,938 FCHVs were trained in Nepal's ECP Program's first phase (Table 2). Of the service providers trained, nine were physicians.

Pre- and post-training tests were conducted on 545 service providers to assess their content of depth of knowledge gained. A comparison of the pre- and posttraining test scores demonstrate that service providers were originally lacking essential knowledge about ECP before the training, which then improved significantly after the training. Before the training, over onethird of the service providers were not familiar with situations when ECP was appropriate for use; after the training, knowledge of appropriate ECP use increased to nearly 100 percent (Table 3).

Table 2: Number of service providers trained, by
district
\begin{tabular}{|llll|}
\hline District & Service & FCHV & Total \\
& provider & & \\
\hline Kathmandu & 233 & 1,166 & 1,399 \\
Bhaktapur & 101 & 189 & 290 \\
Lalitpur & 170 & 379 & 549 \\
Municipal Corporations & 41 & 204 & 245 \\
\hline Total & $\mathbf{5 4 5}$ & $\mathbf{1 , 9 3 8}$ & $\mathbf{2 , 4 8 3}$ \\
\hline
\end{tabular}

Table 3: Percentage of correct answers assessing service provider's understanding of proper ECP use

\begin{tabular}{|lcl|}
\hline Situations & Pre-test & Post-test \\
\hline $\begin{array}{l}\text { Three OCPs were missed in a given } \\
\text { cycle }\end{array}$ 56 & 98 \\
Missed one progestin-only OCP in a & \\
given cycle & 10 & 3 \\
Missed injection due date and had & \\
unprotected intercourse & 67 & 96 \\
Condom leaked/slipped & 82 & 98 \\
Rape & 81 & 97 \\
Intercourse without any FP method & 76 & 97 \\
Do not know & 3 & 3 \\
\hline Total & $\mathbf{5 4 5}$ & $\mathbf{5 4 5}$ \\
\hline
\end{tabular}

Figure 2 displays the average pre- and post-test scores demonstrating service providers' ECP knowledge. The results show that about 50 percent of service providers had some knowledge of correct ECP use before the training. Yet the most notable results are the post-training test scores, which increased to almost 100 percent in many categories. 


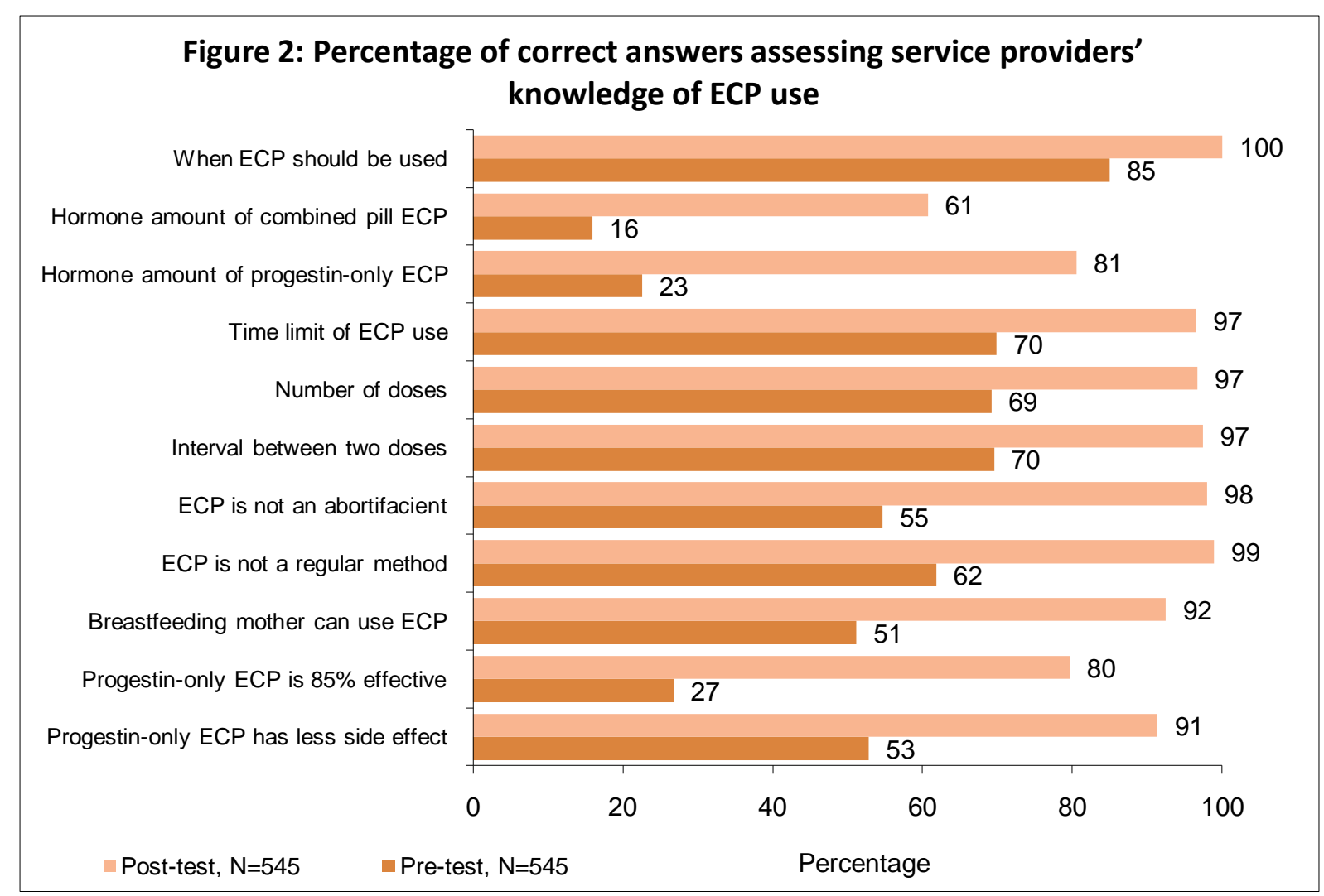

However, a few service providers did not demonstrate a complete understanding of ECP even after the training. For example, 80 percent of service providers could indicate the effectiveness of ECP after participation in the training (Figure 2), yet this leaves 20 percent of participants who continued to give an incorrect answer, or no answer at all. Also, the participants' knowledge of ECP functioning proved incorrect or incomplete among over 30 percent of service providers (Figure 3). The quality of training and participant's understanding of training content should be followed during this program's scale up, as should other programs implemented in similar settings.

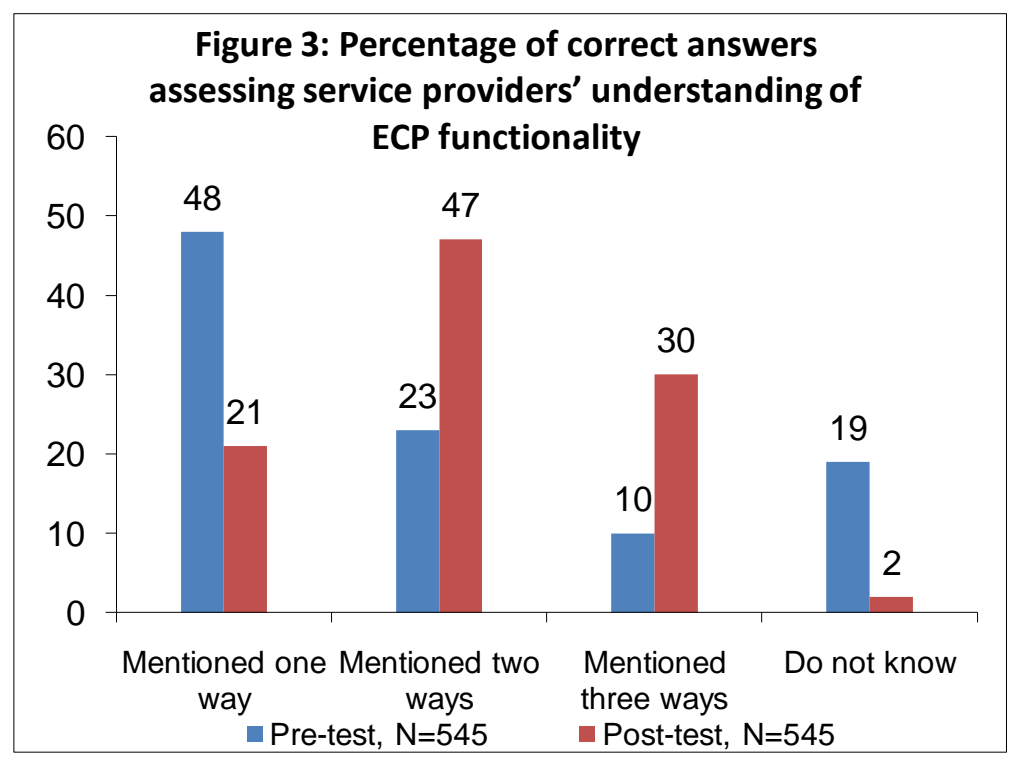

Further analysis shows that among service providers trained, physicians had better knowledge than the paramedics in all aspects of ECP before the training. However, both paramedics and physicians had the same level of knowledge, in regards to ECP information, after participating in training. This indicates that the training was successful, and that both physicians and paramedics can be easily and equivalently trained to provide ECP services. 
Figure 4 is a graphical depiction of service providers' knowledge about ECP side effects. Knowledge about side effects was very poor before the training, and improved significantly after the training.

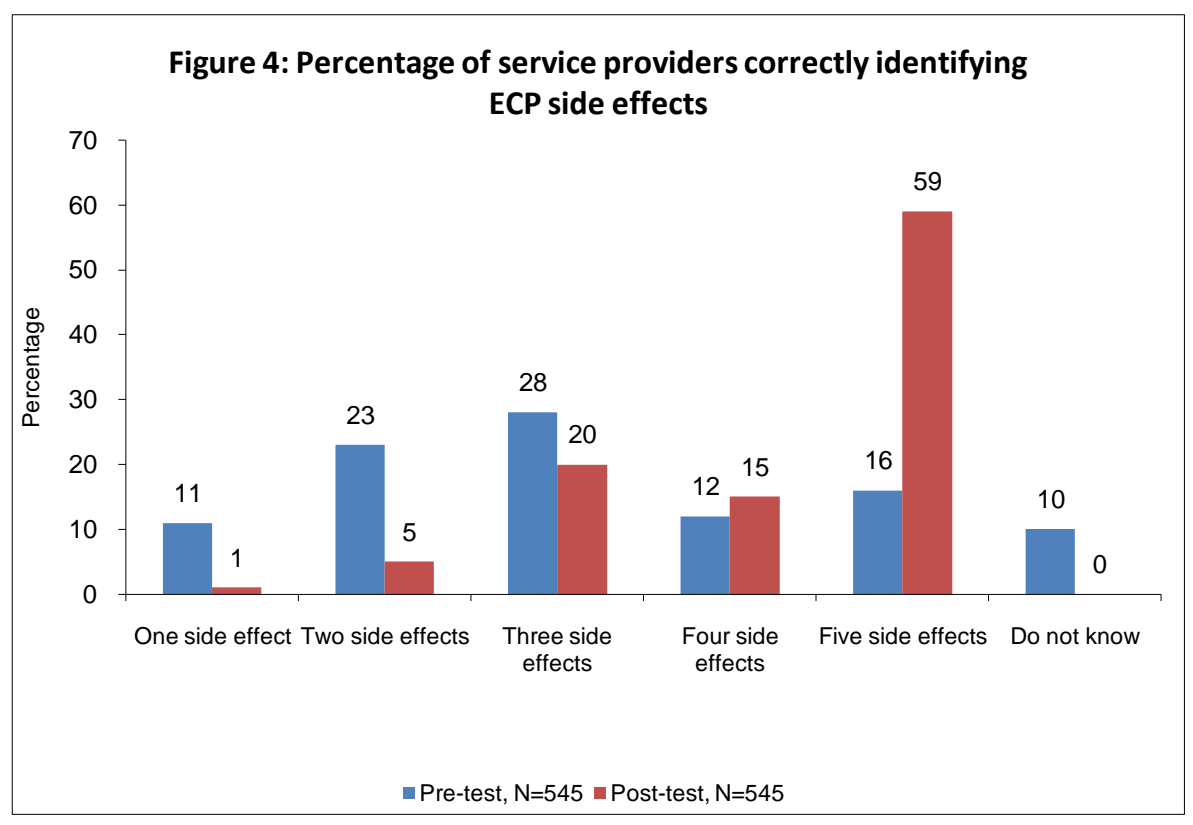

\section{Findings from Monitoring Training Sessions}

Of the 24 training sessions, six were attended by the NHTC, FHD, DPHOs, and NFCC officials. A monitoring checklist developed by the Population Council was used by these officials to assess the quality of the trainings, capturing both organizational and technical aspects.

Analysis revealed that training was organized efficiently and completed satisfactorily in all sites. The training sessions were well planned and trainers came prepared to conduct the various sessions. Training sessions were noted to be interactive and participants were encouraged to ask questions. Pre- and post-training findings revealed an excellent transfer of knowledge to trainees, yet additional improvement is always encouraged, specifically among FCHVs training sessions.

\section{Retention of Service Providers' Knowledge}

Service providers' knowledge retention was assessed four months after training, as part of the program's monitoring system. Ninety service providers were selected randomly from the 545 providers originally trained; each administered the post-test questionnaire and was also interviewed. Figure 5 shows that the retention of knowledge on

\section{Figure 5: Percentage of correct answers in service} provider's knowledge retention test

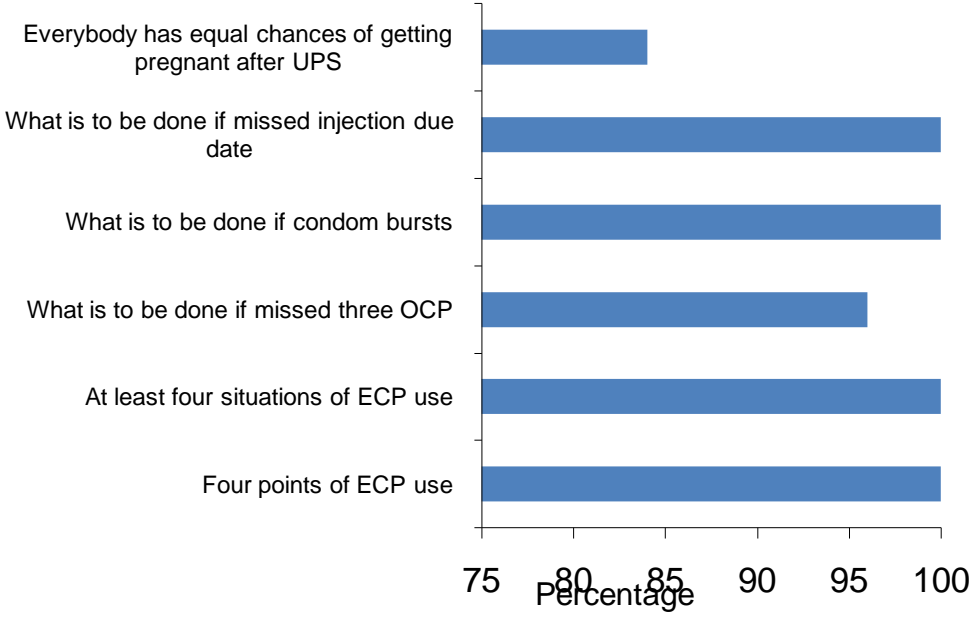


selective issues of ECP use among providers was very high, and in some cases knowledge was higher than that immediately following training. This improvement is somewhat expected, as providers are exposed to additional ECP materials and information during method provision and counseling.

\section{ECP Uptake}

Despite hundreds of service providers trained, the actual use of ECP remained poor. Table 4 shows that only 240 packets of ECPs were used in three intervention districts during the first 11 months of intervention. Use of ECP was higher in the Kathmandu districts, compared Table 4: Use of ECP (November 2006 - October 2007)

\begin{tabular}{|c|c|c|c|}
\hline District & Municipality & DPHO & Total \\
\hline Bhaktapur & -- & 36 & 36 \\
\hline Katmandu & 37 & 116 & 153 \\
\hline Lalitpur & 7 & 44 & 51 \\
\hline Total & $\mathbf{4 4}$ & $\mathbf{1 9 6}$ & $\mathbf{2 4 0}$ \\
\hline
\end{tabular}

with the other two study

districts. Most ECPs were distributed though government health facilities (82\%), and only 18 percent of ECPs were provided by Municipal Health Centers.

The most notable reason for ECP's poor uptake was likely the government's decision to limit ECP distribution to health clinics and prevent FCHVs from distributing ECP, thus limiting access to the contraceptive method. Given Nepal's compromised landscape, it is difficult for many women to reach health facilities that may be far distances over rough terrain. This is especially pertinent considering the short timeframe that ECP is effective after unprotected sex. One last barrier affecting ECP uptake is the poor functioning of the health system and the low number of staff available at clinics and health posts. Rapid appraisals during the project period repeatedly found that the providers were not present during the clinic working hours, decreasing the overall functioning of the clinics and discouraging women from seeking care there.

\section{Sources of ECP Information}

In-depth interviews with ECP users revealed that the two major sources of ECP information were the service providers at the clinics $(33 \%)$ and the FCHVs $(33 \%)$. Other sources of information included MCHWs (12\%), ANMs (8\%), friends (8\%), husbands (3\%), and mothers $(2 \%)$. Analysis revealed a higher level of ECP knowledge among clients counseled by paramedics, compared with those receiving their information from other sources. The diffusion of ECP information through friends and family networks is helpful in increasing awareness about ECP in general, but is not an ideal source of client information about indications for, and proper use of, ECP.

\section{Socio-demographic Characteristics of ECP Users}

Analysis of the 240 ECP-user registration forms revealed that most (85\%) ECP users were using at least one contraceptive method when the act of unprotected sex event took place, requiring use of ECP. ECP users were mostly 25 to 30 year old women, with at least one child. Approximately 70 percent of them resided in rural areas. This rural demographic is important when assessing the most appropriate ECP distribution outlets. Most women were 
housewives (68\%) and a small percentage of users were farmers (10\%). There were no differences in the rate of ECP use between literate and illiterate women.

\section{Reasons for ECP Use}

Forty percent of the women using ECP reported using the contraceptive method because of condom breakage. Another 28 percent reported usage due to a delay in their Depo injection. Other reasons for ECP use included missing OCP for three or more days (16\%) and intercourse without any method (15\%).

In-depth interviews were conducted with $60 \mathrm{ECP}$ users to provide additional insight into their reasons for ECP use. In addition to those listed above, explanations for ECP use include forced sex by the husband, risky behaviors or delays in withdrawal during unprotected intercourse. These specific responses may not have been revealed in a quantitative questionnaire as they are highly-sensitive issues that may be accompanied by fear, stigma or embarrassment. This method of qualitative data collection was important to gain a complete understanding of ECP use and user dynamics.

The same interviews further indicated that most women using ECP were at risk for possible pregnancy due to unprotected intercourse. Women recognized that carrying through with the unwanted pregnancy was one alternative to ECP use, and abortion was another alternative reconciliation. It is interesting to note that only a few husbands had similar interpretations of the possibility of an unwanted pregnancy, and many times, they themselves collected the ECP from the health clinics for their wives.

\section{Findings from Client-Provider Interactions}

Numerous client-provider interactions were observed during the program's duration, and a checklist was used to evaluate the content and quality of these interactions. Considerations were made for a provider's proper greeting and assessment of the patient's need for ECP, the content and quality of information provided to the client, his/her counseling skills and use of IEC materials and aides during the counseling session. A total of 47 client-provider interactions were assessed.

Analysis of the checklist (Table 5) shows satisfactory performance from all service providers, with regards to quality of care and provision of ECP. All providers greeted the clients and asked about their episode of unprotected sex.

The extent of ECP information provided to the clients was relatively satisfactory. Some information was not consistently shared with all clients, and the overall depth of information addressed could be improved, yet overall findings from these observations are positive. One area of service-delivery that requires improvement is the amount of information that is provided to clients about ECP's effectiveness. Only 43 percent of clients were informed of ECP's level of effectiveness, especially in terms of other contraceptive methods. Additionally, providers should more readily encourage clients to ask questions. Use of flipchart and job aides during counseling, maintaining privacy, and showing non-judgmental attitude during provision of services, were considered to be satisfactory according to observations. 
Table 5: Findings from client-provider interactions

\begin{tabular}{|c|c|c|}
\hline Observation on client-provider interaction & $\begin{array}{c}\text { Percentage } \\
\text { asked }\end{array}$ & Remarks \\
\hline Questions Asked on & 100 & Satisfactory \\
\hline Marital status & 100 & Satisfactory \\
\hline When and how UPS occurred & 100 & Satisfactory \\
\hline Last date of menstruation & $\begin{array}{c}\text { Percentage } \\
\text { provided } \\
\text { information }\end{array}$ & \\
\hline Information provided & 100 & Satisfactory \\
\hline Situation when ECP could be used & 100 & Satisfactory \\
\hline How ECP should be used & 77 & $\begin{array}{c}\text { Needs } \\
\text { improvement }\end{array}$ \\
\hline Told that ECP is not an abortive & 87 & $\begin{array}{c}\text { Needs } \\
\text { improvement }\end{array}$ \\
\hline $\begin{array}{c}\text { ECP is not a regular method of contraception; it is a } \\
\text { backup contraceptive method }\end{array}$ & 43 & $\begin{array}{c}\text { Needs } \\
\text { improvement }\end{array}$ \\
\hline Effectiveness of ECP & 79 & $\begin{array}{c}\text { Needs } \\
\text { improvement }\end{array}$ \\
\hline How to come to the regular method after ECP use & $\begin{array}{c}\text { Percentage } \\
\text { checked }\end{array}$ & $\begin{array}{c}\text { Satisfactory } \\
\text { Satisfactory }\end{array}$ \\
\hline Checked whether & 98 & Satisfactory \\
\hline $\begin{array}{l}\text { Clients understood information/took feedback from } \\
\text { clients }\end{array}$ & 89 & Satisfactory \\
\hline Flipchart available on provider's table & 87 & Satisfactory \\
\hline Used flipchart during counseling & 98 & Needs \\
Ensured privacy during counseling & 100 & $\begin{array}{c}\text { Needs } \\
\text { improvement }\end{array}$ \\
\hline $\begin{array}{l}\text { Provided treatment and counseling with non- } \\
\text { judgmental attitudes }\end{array}$ & 64 \\
\hline $\begin{array}{l}\text { Poster posted at a prominent place } \\
\text { Encouraged clients to ask questions }\end{array}$ & 75 & $\mathbf{4 7}$ \\
\hline Total Number of observations made & & \\
\hline
\end{tabular}

\section{Sharing ECP Information}

In-depth interviews with the ECP users showed that 80 percent of the users informed and discussed ECP with friends and/or relatives. Of those who shared information, 65 percent disseminated it within their same households, 25 percent shared with neighbors, and 11 percent spoke to others in their same village. Furthermore, 96 percent of ECP users reported sharing the ECP leaflet with their husband, 62 percent with friends, and 15 percent with their neighbors. Spreading messages and sharing IEC materials with others is an effective way of increasing awareness about ECP.

\section{ECP User Knowledge about the Method}

Analysis of in-depth interviews and information collected during follow-up survey of the 61 ECP users revealed that most ECP users had adequate and correct knowledge about ECP use. Ninety-eight percent of ECP users correctly identified when the first dose of ECP should be taken, 96 percent indicated the correct number of doses, and 100 percent identified the correct interval between doses. Ninety-five percent of users completing the questionnaire provided correct answers on ECP use questions. 


\section{Pregnancy Prevention}

Questions after ECP administration revealed that 93 percent of ECP users were able to avert an unwanted pregnancy. Seven percent of women did get pregnant after ECP use; these pregnancies were most likely due to a delay in ECP administration, or mismanagement of ECP doses.

\section{Use of Contraception Before and After the Use of ECP}

\begin{tabular}{|c|c|c|c|}
\hline \multirow{3}{*}{$\begin{array}{l}\text { Almost all women } \\
\text { interviewed in this } \\
\text { study practiced some } \\
\text { method of regular } \\
\text { contraception during }\end{array}$} & \multicolumn{3}{|c|}{ Table 6: Use of contraception before and after use of ECP } \\
\hline & Methods & $\begin{array}{c}\text { Before the use } \\
\text { of ECP } \\
\text { (Number) }\end{array}$ & $\begin{array}{c}\text { After the use } \\
\text { of ECP } \\
\text { (Number) }\end{array}$ \\
\hline & Condom & 25 & 26 \\
\hline ECP usage. The three & Injection & 17 & 19 \\
\hline most common methods & Oral pills & 9 & 6 \\
\hline used were the male & IUD & 0 & 1 \\
\hline $\begin{array}{l}\text { condom, injections, and } \\
\text { oral contraceptive pills. }\end{array}$ & $\begin{array}{l}\text { Traditional methods (withdrawal, } \\
\text { safe period, periodic abstinence) }\end{array}$ & 9 & 9 \\
\hline positive shift to & No method & 1 & 0 \\
\hline traceptive use, & Total & 61 & 61 \\
\hline
\end{tabular}

particularly use of long-

term methods, was seen after the use of ECP. Table 6 shows that all women reverted back to their regular methods of contraception, or to more reliable methods, after ECP use. This finding disproves the assumption that women who use ECP would use the method as a regular family planning method, in place of other available methods, when made available free-of-cost and/or over-the-counter.

\section{Findings from Monitoring Service Provision}

To assess the actual provision of ECP services, field visits were conducted in most outlets and clinics participating in the program. Meetings were held for service providers and FCHVs throughout each district, where project staff reinforced messages and program objectives to those parties distributing ECP products and information. Additionally, district authorities were requested to allocate 15 minutes of their monthly meetings to address the ECP program in order to review the program's progress and refresh concerned parties on important aspects of ECP.

Monitoring visits identified several bottlenecks within the implementation process. For one, it was observed that brochures were not regularly distributed to all clients visiting health facilities. Furthermore, providers did not always integrate ECP counseling into counseling of other spacing methods. ECP was regularly omitted from counseling when clients would visit facilities in cases of condom breakage or mistiming of OCP administration. Consequently, these missed opportunities may have contributed to the low ECP uptake in health facilities, and improvements in ECP promotion should be pursued.

To improve client's knowledge about ECP and its use, FHD has taken several measures, including meetings with district authorities and circulating instructions to all ECP service providers. This letter emphasized ECP information for all potential clients, distribution of pills as needed, liberal distribution of IEC materials, and proper record keeping and reporting. 


\section{DISCUSSION}

ECP was incorporated into the National Medical Standards of the Government of Nepal in 2002, yet ECP services were not introduced until 2005. With successful implementation of ECP program in Bangladesh and India serving as frameworks, Nepal introduced ECP into the national program, with assistance from numerous national organizations and technical assistance from the Population Council.

The training model used in Nepal was shown to be effective, with marked improvements in knowledge among most service providers and high knowledge retention rates. Similar to analysis of the Bangladesh and India programs, it was clear that paramedics could provide equivalent ECP services as physicians, and that ECP distribution by FCHVs should be considered as additional means for ECP service delivery.

The uptake and use of ECP was low during the initial stages of the program, yet as ECP knowledge increased, use of ECP also increased. Compromised access to health services (specifically ECP services) continues to hinder complete dissemination of the contraceptive product and information about it, FCHVs are continually unable to provide ECP to clients in the community setting, and distribution is limited to clinic-based health professionals. Additionally, transportation to these health posts and clinics is excessively difficult, as roads are rough and difficult to navigate, and clinics are far from rural areas where many potential ECP users reside. Not incorporating FCHVs in the provision strategy has been identified by the service providers as the single most important problem contributing to the poor uptake of ECP in Nepal. It is strongly recommended that FCHVs are incorporated into the distribution plan for ECP in the expansion phase.

Organizational weakness has always been considered a serious barrier when implementing any new health program. Rapid appraisal visits and discussions with district level officials reflected compromised coordination between the DPHO and the lower level service facilities. Lack of proper supervision and monitoring within the health sector is also very common in rural areas. The ECP program suffered from regular transfers of trained service providers to other districts, and without regular refresher trainings, service providers were often omitting emergency contraceptive counseling and distribution from their delivery services. It is strongly recommended that in the future expansion, all providers should be trained simultaneously (as in Bangladesh's program), or trained personnel should not be transferred during the project period. Capacity building among district management should also be prioritized during the program's expansion phase, when research and evaluation agencies can contribute significantly to program improvement and successful implementation.

The general poor functioning of the health posts and the consistent non-availability of service providers at the facilities often cause delays and nonuse of services for clients seeking family planning services. Because many people in Nepal live in rural areas located in the mountains, providing ECP services at fixed facilities may not be the ideal means for accessibility. Making ECP available within the community, from sources such as the FCHVs and/or local NGO facilities, would substantially increase access to and use of ECP.

The ECP program is regarded as a separate program from other reproductive health services. Because the ECP program was not initially and completely integrated with other RH services, sufficient consideration of its implementation may not have been provided to its implementation. Data records were not maintained properly; IEC materials were not 
distributed completely; and ECP counseling was not offered as frequently as planned. Further integration with the existing family planning program must be emphasized in order to present ECP as another contraceptive option within the overall contraceptive method-mix available, not as a distinct and separate method requiring individualized services. Additional program supervision and ongoing monitoring and evaluation may provide means to improve the program's effectiveness and overall distribution of ECP in Nepal.

There continues to be a huge demand for ECP among Nepal's women and families. Service providers report requests from both married and unmarried women of all ages in need of ECP product and counseling. The number of unwanted pregnancies is consistently on the rise, as is the number of abortions (from both trained and untrained providers). The most notable challenges to ECP distribution in Nepal are continually ensuring accurate and wide-spread diffusion of ECP information to concerned parties, and making certain ECP is accessible to all women, at both district and community levels.

\section{CONCLUSIONS AND RECOMMENDATIONS}

The following conclusions and recommendations have emerged from the Nepal's ECP program's first phase of implementation:

- There is a large unmet need for ECP among Nepalese women; therefore, it must be made available to all potential users. The rise in abortion rates since its legalization, demonstrates the increasing need for all methods of contraception, especially ECP.

- The ECP program must be scaled up in a phased manner, yet the initial phase must be large enough to capture strengths and weaknesses, potential bottlenecks and concerns, as well as the reality of the program's operationalization at fullscale.

- Paramedics are equally efficient and able to provide ECP education and provision as other health professionals, including physicians.

- FCHVs are the primary contact persons for health services within the community and should be included in ECP provision strategy. Local community-based organizations (CBO) and informal groups within the community should also be oriented on dissemination of family planning education and ECP services.

- Mass media, such as television, is an effective means at informing women about ECP and should be included in the program's scale-up. Women in Nepal learned about India's I-pill (ECP) from Indian television commercials, yet are less familiar with Nepal's public-sector product, Postinor 2.

- Supervision and monitoring was a missing link in the ECP Program's implementation. Strong supervision and monitoring activities should be included during the program's scale-up.

- Provision of ECP services could serve as a bridge for other reproductive health services, particularly for family planning counseling and promotion of long-term contraceptive method use.

- Long-term technical assistance for Nepal's public and NGO system would greatly assist in capacity-building and management of the ECP Program. Independent research and evaluation agencies, such as NFCC, could also provide assistance; yet financial constraints exist in its sustainability. The Government of Nepal is willing to scale up the ECP program throughout the entire country, yet resources for training and commodities are a continual challenge. 


\section{UTILIZATION OF THE FINDINGS}

Nepal utilized frameworks and strategies implemented in the ECP programs from both Bangladesh and India. FHD has presented training outcomes and Phase I findings to the United National Population Fund (UNFPA), in efforts to seek further funding and support for the program's scale-up. These efforts strive towards UNFPA's larger goal of reducing unintended pregnancies and maternal mortality. The initiative to scale up is likely. UNFPA agreed to provide support to scale up Nepal's ECP program in two districts (Sindhupal Chowk and Lumjung) in 2007 and additional districts in 2008. UNFPA will provide funds for training and procurement of ECP pills; NFCC will provide technical assistance during the implementation of program activities. 


\section{REFERENCES}

Consortium for Emergency Contraception. 1996. "Emergency Contraceptive Pills: A Resources Packet for Health Care Providers and Program Managers." Seattle: Consortium for Emergency Contraception.

Consortium for Emergency Contraception. 2000. "Emergency Contraceptive Pills: Medical and Service Delivery Guidelines." Seattle: Consortium for Emergency Contraception.

Consortium for Emergency Contraception. 2002. "Expanding Global Access to Emergency Contraception: A Collaborative Approach to Meeting Women's Needs." Seattle: Consortium for Emergency Contraception.

CREHPA. 2003. "Providers Perspective on Prevention Practices of Unwanted pregnancy and Use of Emergency Contraception". Kathmandu, Nepal: CREHPA.

CREHPA. 2003. "Understanding Culturally Specific Pregnancy Prevention Practices Following Unprotected Intercourse among Young Couples of Different Communities of Nepal." Kathmandu, Nepal: CREHPA.

CREHPA. 2004. "National Workshop on Developing Sustainable Strategies for Introducing Emergency Contraception in Nepal." Workshop Report, Kupondole 16 December. Latitpur, Nepal: CREHPA.

Department of Health Services, Nepal. 2004. Annual Report 2002-2004. Kathmandu, Nepal: Department of Health Services.

Family Health Division, Ministry of Health, New Era, ORC Macro. 2002. Nepal Demographic and Health Survey 2001. Kathmandu, Nepal: Family Health Division, Ministry of Health, New Era, ORC Macro.

Family Health Division, Nepal. 2007. Technical Committee for Implementation of Comprehensive Abortion Care (TCIC). Katmandu, Nepal: Family Health Division.

Family Health International. 1999. Contraceptive Technology Updates Series. North Carolina: Family Health International.

Hatcher, Robert A., Ward Rinehart, Richard Blackbuurn and Judith S. Geller. 1997. The Essential of Contraceptive Technology: A Handbook for Clinic Staff. Baltimore: Johns Hopkins School of Public Health, Population Information Program.

Hossain, Sharif Mohammed Ismail and Syeeda Tazneen Waris. 2005. Master Trainers Training on Emergency Contraceptive Pills (ECPs) of the Government Officials of Rajshahi, Khulna, Sylhet and Barishal and Chittagong Divisions. Dhaka, Bangladesh: Directorate of family Planning.

Hossain, Sharif Mohammed Ismail, M. E. Khan, Moshiur Rahman, Jahir Uddin Ahmed, Mirza A. H. M. Bareque and Bishnupada Dhar. 2003. Emergency Contraceptive Pills: A training Manual. Dhaka: Population Council/FRONTIERS and Directorate of Family Planning.

Khan, M. E. and Sharif Mohammed Ismail Hossain. 2001. "Introducing Emergency Contraception in Bangladesh: A Feasibility Study." Research Updates 1. Dhaka, Bangladesh: Population Council.

Khan, M. E. and Sharif Mohammed Ismail Hossain. 2003. "Introducing Emergency Contraceptive Pills in Bangladesh: Lessons Learned and Its Policy Implication." Research Update 3. Dhaka: Population Council/FRONTERS.

Khan, M. E. and Sharif Mohammed Ismail Hossain. 2005. Introducing Emergency Contraceptive Pills in Bangladesh: A feasibility Study. Final Report. Dhaka: Population Council/FRONTERS.

Khan, M. E., Sharif Mohammed Ismail Hossain and Moshiur Rahman. 2002. "Training Service Providers on Emergency Contraception: Lessons Learned from an OR Study." Research Updates 2. Dhaka, Bangladesh: Population Council/FRONTERS. 
Khan, M.E. and Sharif Mohammed Ismail Hossain. 2005. Building national capacity to delivery emergency contraceptive pills. Research Update 5. Dhaka: Population Council/FRONTERS.

Nayyar, Anjali. 2000. Emergency Contraception: Know Your Option. India: Population Council.

UNDP/UNFPA/WHO/World Bank Special Programme of Research, Development and Research Training in Human Reproduction. 2001. Use of Emergency Contraception Pills could Halve the Induced Abortion Rate in Shanghai, China. Social Science Research Policy Briefs. Series 2. No 1.

WHO, UNICEF and UNFPA. 2004. Maternal Mortality in 2000: Estimates developed by WHO, UNICEF and UNFPA. Geneva: World Health Organization.

World Health Organization. 1998. Emergency Contraception: A Guide for Service Delivery. Geneva: WHO.

World Health Organization. 1999. Reduction of Maternal Mortality: A Joint WHO/UNFPA/UNICEF/World Bank Statement. Geneva: WHO. 